\title{
Redes agroalimentares alternativas e consumo crítico: o caso das feiras orgânicas de Porto Alegre
}

\author{
Graciela Cristina Dillemburg Martil ${ }^{2}$ \\ Flávio Sacco dos Anjos ${ }^{3}$
}

\section{Resumo}

As quatro últimas décadas coincidem com a aparição do que se convencionou chamar "redes agroalimentares alternativas". Os inúmeros escândalos, a incerteza generalizada e a busca por alimentos mais saudáveis figuram em destaque, dentro de um movimento mais amplo denominado "turn of quality", em que a ideia de qualidade ultrapassa os atributos estritos e tangíveis do produto. As feiras orgânicas de Porto Alegre se inserem dentro das transformações que incidem sobre o mundo da alimentação em geral. O foco do estudo é elucidar as circunstâncias que contribuíram para o seu surgimento, assim como as mutações que esse sistema local de abastecimento experimenta desde o seu surgimento. A pesquisa busca mostrar que as feiras orgânicas consistem num espaço social singular em que operam muito mais do que operações de compra e venda de alimentos. Não obstante, há desafios em relação ao futuro, especialmente os desdobramentos decorrentes do incremento da demanda e risco de convencionalização.

Palavras-chave: Canais curtos de comercialização. Consumo crítico. Feiras livres. Agricultura orgânica. Agroecologia.

I Este trabalho não poderia ter sido realizado sem o apoio do Conselho Nacional de Desenvolvimento Científico e Tecnológico, através da concessão de bolsa de produtividade ao segundo autor (processo n 305086/20189), bem como à Coordenação de Aperfeiçoamento de Pessoal de Nível Superior, pela concessão de bolsa de Professor Visitante Sênior (Prlnt-Capes Program, processo n 88887.363956/2019-00), a qual viabilizou sua missão científica (2019-2020) junto ao Instituto de Estudios Sociales Avanzados (Córdoba), ligado ao Consejo Superior de Investigaciones Científicas de Espanha, a quem agradece a acolhida.

2 Mestre em Sociologia pela Universidade Federal de Pelotas (UFPel) (2016), é professora-formadora (Bolsista Capes/UAB) do Curso de Licenciatura em Filosofia da UFPel.

3 Professor Titular da Faculdade de Agronomia da Universidade Federal de Pelotas (UFPel) e do Programa de Pós-Graduação em Sociologia (UFPel). É doutor em Sociologia pela Universidade de Córdoba, Espanha (2000). atribua a autoria da obra, forneça um link para a licença, $e$ indicar se foram feitas alterações. 


\section{Introdução}

O pensamento ocidental foi bastante influenciado pela Escola de Frankfurt, vertente intelectual que, entre outros aspectos, consolidou as bases e os rumos da sociologia e da filosofia crítica universais. Filósofo, sociólogo, compositor musical e crítico de arte, Theodor Adorno foi um de seus grandes expoentes, assim como do neomarxismo europeu. Sua visão filosófica iluminou o debate sobre a natureza e o impacto da indústria cultural e dos meios de comunicação de massa, em meio ao surgimento dos grandes conglomerados da comunicação audiovisual.

Com Max Horkheimer, Adorno estabeleceu uma parceria intelectual que ensejou a criação de inúmeros trabalhos, entre os quais $A$ dialética do esclarecimento (ADORNO; HORKHEIMER, [1944] 1995), considerada como uma das mais emblemáticas obras do século XX. Nela vemos cristalizados o desencanto de uma sociedade que renuncia à emancipação dos indivíduos, bem como aos compromissos mais amplos de transformação social num mundo em estado constante de ebulição.

Até o final de sua vida, Adorno seguiu defendendo a relevância do pensamento crítico. Cada ato crítico há que ser visto como se fora uma garrafa jogada ao mar para destinatários ignorados, cuja mensagem essencial é a de que a indústria cultural esconde o que permanentemente promete aos seus consumidores, qual seja, a ideia de uma felicidade plena centrada na materialidade dos objetos de fruição individual.

A ascensão dos grandes impérios agroalimentares (PLOEG, 2008), com suas cadeias globais de suprimento e distribuição, espalhadas pelos quatro quadrantes do planeta, há que ser vista muito além de um fenômeno inerente ao surgimento das metrópoles, de um acelerado processo de urbanização e de mudanças dos padróes de consumo. Em verdade, trata-se de um processo que se apoia nos apelos tanto ao consumo quanto à força dos instrumentos de persuasão de uma indústria cultural cuja quintessência descansa nas grandes cadeias de fast food, ou no que Ritzer (1996) define como uma sociedade macdonaldizada, com sua linguagem universal de símbolos e suas poderosas ferramentas midiáticas de sedução e encantamento. Não raras vezes, a embalagem, o ambiente e os adereços adquirem um peso maior do que o produto alimentício contido em seu interior. 
Paralelamente, desde as quatro últimas décadas, o mundo moderno trouxe consigo uma desconcertante sucessão de escândalos agroalimentares. No rosário interminável de episódios, constam, em destaque, a comercialização de carne radioativa no Japão, o hambúrguer com carne de cavalo no Reino Unido, a contaminação por Escherichia coli na Alemanha, a síndrome da vaca louca, a gripe aviária e suína, ou mesmo as adulteraçóes do leite UHT no Brasil com a adição de ureia, formol e água oxigenada, as quais deflagraram a operaçáo "Leite Compensado", levada a efeito pela Polícia Federal, desde 2013, que permanece inconclusa até o momento de finalização deste artigo.

Esses e tantos outros episódios não fazem outra coisa senão 'alimentar' um clima de incredulidade e suspeição sobre o que hodiernamente estamos consumindo. Toda a polêmica atual em torno ao mundo da alimentação se encaixa perfeitamente dentro do conceito de "sociedade de risco" enunciado pelo sociólogo alemão Ulrich Beck. Acusado de ser um teórico do catastrofismo (MOL; SPARGAAREN, 1993)4, Beck (1992) assevera que, na sociedade industrial, a estratificação social e os conflitos estavam ligados à divisáo da riqueza, enquanto na sociedade atual vivemos um tempo marcado pela divisão e administraçáo de riscos (ecológicos, químicos, econômicos, nucleares, genéticos etc.). Se o perigo parece associado à fatalidade, a ideia de risco remete à exposição voluntária e calculada de um dano, o qual está normalmente ligado a uma estimativa de seus efeitos.

As mutaçóes operadas no mundo da alimentação refletem com extrema claridade não somente a natureza e extensão dos riscos a que estamos expostos, mas também a fragilidade das instituiçóes de controle e as incertezas em torno aos sistemas peritos, a quem foi dado poder justamente para assegurar o cumprimento de normas em matéria de segurança alimentar.

4 Somos conscientes de que os riscos atuais afetam indistintamente o conjunto dos indivíduos, independentemente de sua condição social (e.g., a poluição do ar ou da água). Todavia, atingem sobretudo os grupos sociais mais frágeis, dado que estão mais expostos e menos preparados para reagir às adversidades. Enquanto consumidores, eles terão menor poder de compra, adquirindo produtos alimentares de qualidade inferior cuja procedência, em boa medida, é absolutamente desconhecida. No momento de finalizar este artigo, desembarcarão no Brasil 17 toneladas de carne de frango que foram rechaçadas no Reino Unido por contaminação de salmonela. A atual Ministra da Agricultura do Brasil (Tereza Cristina) afirma que a aludida mercadoria pode ser revendida para o mercado nacional, a qual, seguramente, será consumida pelos mais pobres do país. 
Vale destacar que se fortalecem tanto a percepção dos indivíduos em termos de "certeza da incerteza" quanto a necessidade de encontrar formas de convivência e de enfrentamento em face de um cenário cada vez mais inseguro e desafiador.

Há diversos desdobramentos decorrentes da percepção dos riscos por parte da população em geral. Para os objetivos deste artigo, dois são particularmente importantes. $O$ primeiro deles tem a ver com a emergência de novas formas de solidariedade em substituição às formas tradicionais, que estavam fortemente ligadas à classe ou comunidade (BECK; GIDDENS; LASH, 1997). Tal mutação se vê reforçada pelos visíveis sinais de esgotamento do Estado de bem-estar social nas sociedades contemporâneas.

O segundo desdobramento, que guarda estreita ligação com o primeiro, tem a ver com o colapso dos canais convencionais de exercício da política e da cidadania, e.g. as estruturas partidárias e sindicais. Esse quadro enseja o surgimento do que Beck (1992, p. 23) denomina de uma subpolítica, a qual propugna "configurar a sociedade a partir de baixo". Como bem descreveu Guivant (2001, p. 101), na visão de Beck, a subpolítica

[...] distingue-se da política (na acepção do sistema político oficial), por envolver atores que são outsiders desta última esfera (grupos profissionais e ocupacionais, a intelligentsia técnica de companhias, institutos de pesquisa e administração, trabalhadores qualificados etc.) e que passam a participar do debate público sobre diversos tipos de assunto.

Definitivamente, um dos grandes assuntos do debate público atual é a questão da alimentação do ponto de vista dos dilemas entre o que podemos e o que não podemos consumir. $\mathrm{O}$ 'enigma da esfinge' não se resolve com a observância da aparência do produto, da narrativa aderida à embalagem que evoca o processo que lhe ensejou, a origem ou lugar em que foi produzido ou elaborado. Trata-se, entre outros aspectos, de reconstruir as pontes que foram sendo rompidas, ao longo das cinco últimas décadas, entre produtores e consumidores, desde que se impôs um poderoso modelo de produção, consumo e abastecimento - um modelo centrado, de um lado, na produção intensiva e padronizada, tributária do uso de agroquímicos e socialmente excludente; de outro, no domínio das grandes cadeias de distribuição e superfícies de varejo. 
A ideia de 'redes agroalimentares alternativas' remete à diversidade de iniciativas que ensaiam outras possibilidades de produção e suprimento de comida, ao conceber estratégias de enfrentamento, sobretudo no mundo ocidental, aos efeitos deletérios engendrados pelos grandes impérios agroalimentares. As feiras livres, em boa medida, exprimem uma faceta dessa tendência, especialmente as que se baseiam na comercialização de produtos orgânicos ou ecológicos 5 .

Esse é precisamente o caso das feiras orgânicas de Porto Alegre, as quais guardam uma história que remete à atuação de uma militância difusa que integra produtores, consumidores, técnicos e ativistas de uma causa que, como oportunamente veremos, extrapola os cânones da teoria da escolha racional (BIANCHI; MURAMATSU, 2005) ou as armadilhas do utilitarismo economicista e vulgar (CAILLÉ, 2001).

As feiras livres ecológicas de Porto Alegre são entendidas aqui não somente como equipamento público de distribuição e abastecimento da produção orgânica, mas também como expressão material do que se convencionou chamar de 'redes agroalimentares alternativas'. O propósito deste artigo é examinar se, e em que medida, constata-se, nesse espaço social singular, a emergência ou manifestação do que a literatura científica define como 'consumo crítico', em suas distintas acepçóes e formas de manifestação.

O artigo está organizado, além desta introdução, em quatro outras seçóes. A primeira delas apresenta e discute o conceito de redes agroalimentares alternativas, enquanto a segunda examina a questáo do consumo crítico. A terceira analisa a trajetória das feiras orgânicas de Porto Alegre, centrando a mirada no diálogo com a matriz teórica que inspirou

5 Existe grande controvérsia na terminologia empregada nesse âmbito, sendo esse um terreno de disputas tanto do ponto de vista acadêmico quanto ideológico. A agricultura orgânica é entendida como uma forma de produzir que exclui o uso de produtos de síntese (adubos sintéticos, agrotóxicos etc.). Todavia, no caso da agroecologia, tais imperativos técnicos são acrescidos de requisitos cruciais, tais como o respeito às justas relações de trabalho nos diversos elos que unem a produção ao consumo, bem como em termos dos compromissos éticos mais amplos com a preservação dos recursos naturais. Com isso, poder-se-ia admitir que todo produto agroecológico é orgânico, mas a recíproca não é verdadeira. A legislação brasileira optou pelo uso do termo "orgânico", enquanto na Itália e França a ênfase recai sobre o adjetivo "biológico" nas alusões a essa forma de agricultura. Neste artigo, consideramos os termos como equivalentes, admitindo que essa discussão, ainda que pertinente, extrapola os objetivos do trabalho. 
tal abordagem. A quarta e última seção reúne as considerações finais deste estudo. A etapa de campo se desenvolveu durante o ano de 2015, fazendo uso da observação participante, pesquisa documental ${ }^{6}$ e aplicação de entrevistas (22) em profundidade com produtores ecologistas, consumidores, administradores das feiras, agentes da Secretaria Municipal de Indústria e Comércio e outros atores sociais ligados à dinâmica dessas feiras. Paralelamente, houve a participação em eventos organizados pelas duas principais feiras da regiáo central de Porto Alegre (bairros Bonfim e Menino Deus), assim como visitas às propriedades rurais onde residem e trabalham os produtores. As entrevistas foram realizadas com o uso de gravador, havendo sido integralmente transcritas e posteriormente organizadas e analisadas com o auxílio de software específico (N Vivo).

\section{Redes agroalimentares alternativas}

A literatura anglo-saxã consagrou o termo "alternative food networks" (doravante $\mathrm{AFN}$ ) nas alusôes às mais diversas iniciativas e estratégias de construçáo da qualidade que divergem ou contrariam o mainstream da produção, distribuição, abastecimento e consumo de alimentos nos diversos países do mundo. Com efeito, a obra elaborada por Goodman, Dupuis e Goodman (2012) oferece uma revisão crítica da emergência e disseminação de AFN e da luta em defesa de valores éticos ante o poder exercido pelas cadeias globais de suprimento e distribuição de alimentos.

Todavia, se no auge dos anos 1970 os movimentos ambientalistas predicavam a necessidade de construir uma agricultura 'alternativa' ao padrão imposto pelas tecnologias da Revolução Verde (uso intensivo de mecanização, adubos sintéticos, agrotóxicos etc.), a ideia de redes agroalimentares alternativas evoca o primado da construção de 'vias de fuga' ao poder exercido pelos grandes conglomerados que comandam não somente a produção, mas também a transformação, distribuição, comercialização e consumo de alimentos em nível mundial.

Todavia, como aludem Renting, Schermer e Rossi (2012, p. 291), tal conceito mostra-se cada vez mais insatisfatório para compreender a

Basicamente, refere-se à coleta e análise de documentos dos organizadores das feiras (atas, regulamentos etc.) e da Secretaria Municipal de Indústria e Comércio da Prefeitura Municipal de Porto Alegre. 
natureza dos processos que ensejam o surgimento dessas experiências nos países desenvolvidos. Isso ocorre, entre outros aspectos, porque a linha que separa o convencional e o alternativo é cada vez mais tênue, sobretudo quando se sabe, como advertiu Fonte (2010), que ambos os regimes operam dentro de um mesmo espaço econômico - o mercado capitalista -, havendo, entre si, um elevado grau de solapamento e intersecção. Fruto desse cenário, emerge a discussão em torno à 'convencionalização', processo no qual os circuitos de produtos orgânicos tendem a assumir características idênticas às das cadeias ou redes convencionais no que tange às dinâmicas de mercantilização, busca de ganhos à escala, integração vertical, especialização produtiva (GOLDBERGER, 2011) e respostas mercadológicas às demandas de consumidores mais exigentes.

Contrariando essa tendência de convencionalização da produção orgânica, alguns autores (CONSTANCE; CHOI; LYKE-HO-GLAND, 2008; ROSIN; CAMPBELL, 2009) falam de bifurcação do setor de orgânicos. De um lado, estaria o que denominam "indústria orgânica”, constituída por grandes corporaçóes, operaçóes em larga escala, mercados globais e uma inevitável perda (ou descolamento) dos valores fundamentais que originalmente ensejaram essa forma de produção. No extremo oposto, estaria o "movimento orgânico", cuja ênfase recai na produção artesanal, nos mercados locais, no uso de energias renováveis e na preservação ambiental, bem como nos compromissos pautados na justiça social, no comércio justo e na proteção à saúde de quem produz e de quem consome tais artigos.

Uma outra vertente interpretativa analisa as novas redes de cooperação entre consumidores e produtores, em que os primeiros assumem um papel ativo em processos que vão muito além do objetivo de satisfazer necessidades alimentares imediatas e de consumir produtos saudáveis. Referimo-nos, nesse caso, ao que se considera 'redes agroalimentares cívicas' (RENTING; SCHERMER; ROSSI, 2012), que se apoiam sobre valores fundamentais, como solidariedade, reciprocidade, democracia e cidadania.

Ainda no terreno da diversidade de formas com que se exprime o debate sobre AFN, podemos mencionar o caso das 'community supported agriculture' (ALLEN et al., 2003), em que há um compromisso tácito dos consumidores em apoiar, material e simbolicamente, os produtores que 
lhes fornecem o alimento, garantindo-lhes uma renda mensal ou o pagamento antecipado dos produtos. Analisando estudos realizados na Europa e Estados Unidos, é possível perceber que o debate não se concentra apenas na alternatividade em termos econômicos, mas também do ponto de vista da emergência de outros vetores, como no caso da segurança ambiental e equidade social (GOODMAN; DUPUIS, 2002; HENDRICKSON; HEFFERNAN, 2002).

Com base no aporte heurístico da teoria ator-rede, tal perspectiva define AFN como conjunto de práticas e relaçóes contraídas entre produtores e consumidores que emerge no contexto das abordagens pós-estruturalistas de análise do capitalismo, em que a categoria correspondente à alteridade adquire sentido diante de motivaçôes culturais e políticas dos consumidores (GOODMAN, 2003; SASSATELLI, 2009. No âmbito europeu, as AFN são interpretadas não somente a partir do prisma das modificaçôes nos modelos de consumo, mas também do ponto de vista da contribuição que oferecem à construção de um novo paradigma de desenvolvimento rural fundado em bases territoriais (PLOEG et al., 2000; RENTING; MARSDEN; BANKS, 2003) e voltado à revitalização de áreas rurais (VENTURA; MILONE, 2005; O'CONNOR et al., 2006).

Para os objetivos que persegue este trabalho, importa frisar que convergimos com Sivini (2008, p. 89) quando aponta as limitaçóes das abordagens usuais que se valem do conceito de AFN. No entendimento desta autora, as categorias propostas por Renting, Marsden e Banks (2003) são úteis apenas no que tange ao conteúdo informativo que diferencia essas cadeias curtas de suprimento em relação às convencionais. Tal enfoque não dá conta, portanto, das motivaçóes, bem como das circunstâncias que lhes fizeram emergir. Embora exista uma ingente produção científica sobre a dinâmica das AFN em todo o mundo, há sobradas razóes que apontam para a limitação desse enfoque para responder à complexidade dos aspectos suscitados. Fruto desse entendimento, impóe-se a tarefa de abordar a questão a partir de uma outra perspectiva, por onde transita o debate em torno à construção social da qualidade na produção agroalimentar. Esse é o objetivo da próxima seção. 


\section{Consumo crítico}

A questáo do consumo convencionalmente assumiu uma conotação negativa no contexto das Ciências Humanas. Na acepção marxiana clássica (MARX, 1985), o desejo de consumir aparece vinculado ao fetichismo da mercadoria e ao processo de alienação do trabalhador. Na perspectiva weberiana (WEBER, 1982), associa-se-lhe o prestígio, enquanto para Veblen (1988) a ênfase recai no caráter conspícuo ou ostentatório. Mais recentemente, o tema ganha fôlego a partir de estudos que colocam especial acento no papel do consumo (WARDE, 1997) ou, mais precisamente, nas relaçôes entre consumo alimentar e identidade (BAUMANN, 2007). Já em Bourdieu (2007), o olhar se dirige ao sistema de gostos e preferências das pessoas, em que o ato de consumir é inerente à classe ou categoria social.

A abordagem de Canclini (2010, p. 72) exalta o ato de consumir como exercício de cidadania e "como um lugar de valor cognitivo". Admite, desse modo, que o consumo serve para pensar e atuar, "renovadoramente, na vida social". Destarte, podemos afirmar que se trata de um ato produtor de significados, auxiliando-nos a ordenar o mundo à nossa volta, tornando-o compreensível (DOUGLAS; ISHERWOOD, 2013). Adquirir produtos da economia solidária ou da agricultura familiar representaria, por exemplo, a explicitação do esforço por apoiar tais causas, mas também por forjar uma identidade pautada num sistema de valores que é próprio de cada indivíduo ou dos grupos a que pertence.

O destaque atribuído à questão do consumo como objeto da reflexão científica só é comparável à atenção despertada sobre a comida diante dos aspectos enunciados na primeira parte deste trabalho. Vale recordar que a antropologia sempre se ocupou desse assunto, especialmente porque "[...] o comportamento relativo à comida liga-se diretamente ao sentido de nós mesmos e à nossa identidade social" (MINTZ, 2001, p. 31). Destarte, existe consenso no entendimento de que o ato de comer "representa um poderoso marcador de identidades" (ANJOS; CALDAS; POLLNOW, 2014, p. 20), mas há ainda outros elementos que devem ser trazidos à discussão para delimitar o campo de observação que guiou a realização desta pesquisa.

No entendimento de Ritzer e Jurgenson (2010), ingressamos hoje numa nova fase do capitalismo, caracterizada como a idade do "prosumption" ou 
da "coprodução", na qual produção e consumo se codeterminam reciprocamente. Nesse sentido, cada vez mais, a questão do consumo se entrelaça com os imperativos da sustentabilidade, fazendo emergir uma cidadania ecológica (SEYFANG, 2006) que reposiciona a discussão num outro patamar. Com efeito, os velhos esquemas que colocam em lados opostos o âmbito da produção e o do consumo mostram claros sinais de anacronismo, sobretudo quando temos em mente o fato de que produtores e consumidores constroem outras conexóes em torno a compromissos éticos e cívicos mais amplos.

No limite, a ética de reciprocidade se estabelece não somente entre ambos, mas também, inclusive, com as futuras geraçóes. Trata-se, igualmente, de recuperar o controle sobre a geração, distribuição e consumo da comida. Porém, a cidadania ecológica é especialmente crítica em relação aos esquemas convencionais; denuncia os abusos cometidos em nome da eficiência e praticados pelas grandes cadeias agroalimentares, assim como o desperdício de energia que vai das embalagens plásticas que acondicionam os produtos ao gasto de combustível e de recursos consumidos nas longas cadeias de suprimento e distribuição.

Como bem enunciou Forno (2009, p. 28), o aumento do consumo crítico se liga à emergência de um tipo de cidadáo que a literatura sociológica define como "cidadão crítico", qual seja, um sujeito fortemente identificado com os princípios democráticos, mas imbuído também de uma crescente desconfiança no funcionamento das instituiçóes e nos canais tradicionais de participação política e de exercício da cidadania. Desse modo, o consumo crítico se converte num poderoso instrumento capaz de animar uma participação que vem sendo reiteradamente esvaziada nas arenas convencionais de poder, como é o caso dos partidos políticos, sindicatos e movimentos sociais institucionalizados.

As novas redes que emergem no bojo desses processos apostam na importância de uma ressocialização dos indivíduos, em que a marca fundamental descansa no inevitável diálogo entre o material e o imaterial. Em outras palavras, surgem com força as antinomias entre preço, expressão última de uma convençáo regida pelo dinheiro, e o valor como significação simbólica de um produto, ou entre bem e mercadoria. A questão em 
jogo é o peso crescente do ético das relações subjacentes, em detrimento da dimensão estética de atributos tangíveis presentes no produto a ser consumido.

Neste trabalho, a questão fundamental que almejamos responder é no sentido de examinar se, e em que medida, as feiras orgânicas de Porto Alegre estão revestidas dessa concepção de consumo crítico e se, efetivamente, reverberam essa cidadania ecológica enunciada nesses e em outros estudos que evocamos para delimitar nosso campo de observação.

\section{As feiras orgânicas de Porto Alegre}

As feiras livres colorem a paisagem urbana das diversas localidades do sul do Brasil, como é o caso da capital do Rio Grande do Sul. Porto Alegre conta hoje com 39 feiras livres divididas em sete grupos que funcionam semanalmente, comercializando hortigranjeiros, carnes, derivados de leite, frios e embutidos. Todavia, no caso das feiras livres orgânicas, tem-se a comercialização de produtos obtidos exclusivamente através de um processo produtivo que exclui o uso de agrotóxicos e de adubos sintéticos.

A Secretaria Municipal de Produção, Indústria e Comércio (SMIC) de Porto Alegre é o órgão responsável pela fiscalização e controle desse equipamento público de venda de produtos agroalimentares. A SMIC refere a existência de seis feiras orgânicas regulares na capital gaúcha, sendo que a pesquisa em questão envolveu as três principais, sobre as quais se comentará na continuação.

Uma das grandes frentes que marcaram o surgimento do movimento ambientalista gaúcho, durante a década de 1970, foi a defesa de uma 'agricultura alternativa' ao padrão imposto pelas tecnologias da Revolução Verde, centrado no uso intensivo de agroquímicos, incluindo produtos de elevada toxicidade ${ }^{7}$ empregados no controle de insetos e plantas invasoras (organoclorados e carbamatos).

7 Publicado pela bióloga e ecologista norte-americana Rachel Carson no começo dos anos 1960, o livro Primavera silenciosa (1962) exerceu notável influência à época de sua publicação. Carson foi severamente criticada pelos defensores do padrão intensivo de produção, sobretudo pelas indústrias químicas. Ironicamente, morreu de câncer de mama aos 57 anos, na primavera de 1964, pouco depois de haver proferido um apaixonado discurso no congresso dos Estados Unidos em que chamava a atenção para as políticas de proteção à saúde humana e ao ambiente natural. 
A ideia de uma agricultura alternativa "reveste-se de uma forte conotação contracultural” (ALMEIDA, 1999, p. 65). O movimento ambientalista gaúcho se destacava, à época, no país, tendo o agrônomo e ecologista José Lutzemberger como um de seus grandes expoentes, o qual foi um dos responsáveis pela criação da Agapan, mas também por assentar as bases para a construção do movimento agroecológico no Brasil. Um de nossos entrevistados (feirante agroecologista) resume, em sua fala, a influência exercida por Lutzemberger no que tange aos desafios da transiçáo da agricultura convencional para a agricultura ecológica ou orgânica:

Eu via na imprensa, no jornal, falar deste tal de Lutzemberger. Dai eu fui atrás procurar ele para conhecer. Neste dia conversamos muito. E eu perguntei: Como vou fazer para chegar na propriedade e convencer a familia a produzir sem veneno? Dai ele disse: Anota ai que eu vou te dar os 10 passos da agricultura ecológica. A gente estava andando de carro, e eu consegui anotar. Eu tenho até hoje esta folha de rascunho guardada como uma relíquia para mim.

A criação da Colmeia (1978) ocorre durante o auge do regime militar, momento marcado, entre outros aspectos, por uma dura repressáo a todo tipo de manifestação contrária ao projeto de "modernização conservadora" (BRUM, 1987) e "dolorosa” (GRAZIANO DA SILVA, 1982) imposto desde o golpe de Estado em 1964. O projeto conservador foi o responsável direto pela banalização no uso de agrotóxicos ${ }^{8}$. Nesse sentido, a Colmeia corresponde à primeira cooperativa de consumidores ecológicos do país, cuja história se entrelaça diretamente com a aparição das feiras do gênero no sul do Brasil.

Um grupo de pessoas associadas à Grande Fraternidade Universal ${ }^{9}-$ praticantes da Ioga e do naturismo - e preocupados com uma alimentação saudável resolveu reunir-se para fundar uma organização que se torna responsável por adquirir hortifrutigranjeiros e outros produtos (sobretudo o mel) junto aos agricultores ecologistas de Porto Alegre e de seu entorno.

8 Como é sabido, foi um processo deliberado de incentivo e de subvenções às grandes explorações e à agricultura de exportação, que se aprofunda nas décadas subsequentes com a expansão do agronegócio sobre a região do Cerrado e, mais recentemente, sobre a região amazônica.

9 A Grande Fraternidade Universal é uma organização não governamental filosófica com ramificações em mais de 22 países, havendo sido fundada pelo filósofo francês Serge de la Ferrière em 18 de janeiro de 1948. 
A Colmeia funcionava inicialmente dentro de uma garagem, passando depois a operar num sobrado no coração do tradicional bairro Bonfim. $\mathrm{O}$ número de associados cresce em termos de consumidores, mas também de produtores.

Em 1989, surge a primeira feira livre da Colmeia no espaço urbano de Porto Alegre, que passa depois a chamar-se de "Feira de Agricultores Ecologistas" ou simplesmente FAE. Essa iniciativa acabou por inspirar a aparição de duas outras feiras no bairro Menino Deus. Para os produtores, significava a possibilidade de escoar a própria produção, mas também de buscar o reconhecimento de seu trabalho por parte dos consumidores e divulgar uma causa que afeta, indistintamente, a todas as pessoas como compromisso com a saúde da população e com a preservação ambiental. Um dos agricultores entrevistados descreve nos seguintes termos a criação da FAE:

Aquilo foi uma injeção de ânimo que a gente recebeu! A feira congregou aquele pessoal que estava querendo começar a produzir, mas não tinha muita coisa concreta acontecendo. A feira foi uma coisa concreta que aconteceu [...]. A feira surgiu como sendo o caminho. Esta é a grande porta que se abriu. Já na primeira vez a gente ficou muito satisfeito com a venda. Mas principalmente, a nossa satisfação, foi por causa da receptividade, a acolhida que nós recebemos dos porto-alegrenses, dos consumidores. A gente sentiu que eles queriam muito a feira.

No começo do novo milênio, a Colmeia atravessou problemas financeiros e desentendimentos internos que culminaram no seu fechamento. Os agricultores estavam insatisfeitos com a condução administrativa da cooperativa e, embora buscassem a unidade e a manutenção das conquistas em termos da defesa dos princípios da agroecologia e do conceito construído junto aos consumidores, estavam convictos de que o momento exigia mudanças. Reunidos, os produtores decidiram, então, criar a Associação Agroecológica, instituição jurídica que, doravante, passa a gerir a FAE.

A Feira Ecológica do Bonfim surgiu no início dos anos 1980, por meio da iniciativa de um pequeno grupo de produtores ligados à Associação Gaúcha de Apicultores (AGA). É uma feira tão relevante quanto a FAE, havendo sido criada em funçáo da dificuldade dos produtores em comercializar sua produção, tanto de mel como de outros produtos. Esse fato fez 
com que muitos produtores e consumidores a ela se referissem também como Feira do Mel. Em boa medida, dela passam a fazer parte produtores dissidentes da Colmeia depois da aludida dissolução.

O fato é que ambas as feiras foram regularizadas pela SMIC de Porto Alegre e, embora sejam consideradas feiras distintas, estáo separadas apenas por uma quadra, funcionando dentro de um espaço contíguo. Mesmo após 20 anos, as tensões entre os produtores das duas feiras ainda são evidentes. Um dos pontos de tensão está relacionado às formalidades a serem cumpridas para a comercialização desses produtos. Segundo as normas atuais, todos os produtores devem estar cadastrados como agricultores orgânicos junto ao Ministério da Agricultura, Pecuária e Abastecimento (Mapa). A legislação brasileira dispensa a etiquetagem dos produtos no caso de venda direta ao consumidor, como é o caso das feiras orgânicas, mas, neste caso, o produtor deve estar vinculado a uma associação, bem como cadastrado como tal junto ao Mapa. A divergência ocorre porque, no caso da feira do Bonfim, essa exigência nem sempre foi cumprida com todo o rigor, diferentemente do caso da FAE. A questáo da avaliação da conformidade, ou seja, de respeito às normativas que disciplinam a produção e comercialização dessa classe de produtos, é um aspecto crucial do ponto de vista da garantia e da confiança depositada pelos consumidores.

Criada em 1994, a feira ecológica do bairro Menino Deus é a terceira feira que integra o recorte da pesquisa. As razóes que levaram à sua criaçáo são as mesmas das duas feiras anteriores, estando ela localizada na avenida Getúlio Vargas, mais especificamente no pátio da Secretaria Estadual da Agricultura. Essa feira também é administrada pela Associação Agroecológica, seguindo fielmente os preceitos adotados pela FAE. No começo do novo milênio, Garcia (2004) estimava em cerca de 15 mil o número de frequentadores de sábado da Feira do Bonfim, os quais adquiriam uma produção oriunda de aproximadamente 400 produtores familiares da região metropolitana de Porto Alegre. O número de agricultores se manteve, mas o de consumidores se expandiu sensivelmente.

A SMIC atua como órgão público responsável pela regulação do funcionamento das feiras de Porto Alegre. Com efeito, através da Resolução no 03, de 26 de dezembro de 2012, foi instituído o Conselho das Feiras 
Orgânicas, do qual fazem parte representantes de órgãos técnicos (Ema$\left.\operatorname{te}^{10}\right)$, consumidores, produtores e representantes da Comissão de Produção Orgânica do Rio Grande do Sul, composição esta que guarda total conformidade com o disposto na legislação nacional da produção de orgânicos. Um dos consumidores participantes do Conselho da Feira Ecológica do Menino Deus descreveu nos seguintes termos as suas funçóes:

Esse conselho, na verdade, iniciou por iniciativa de algumas pessoas que, vendo o crescimento das feiras orgânicas, entenderam que seria necessária uma regulamentação para que a coisa não ficasse no oba-oba. E, dentre eles, foi a presença de representantes da Emater, principalmente. Eu tinha uma visão distorcida da Emater, depois que eu comecei a ver que efetivamente eles têm um trabalho muito importante. Então a Emater, juntamente com a SMIC, com produtores, eles começaram a formalizar um documento que acabou se transformando nessa resolução, estabelecendo regras de funcionamento das feiras ecológicas.

O engajamento dos consumidores, desde então, vem se ampliando e até mesmo surpreendendo os demais membros do Conselho de Feiras, situação que fortalece o espaço de interação entre agentes que, convencionalmente, não dialogam entre si na fria relação entre o produzir, o comprar e o consumir, como diariamente ocorre dentro do comércio varejista. Segundo as palavras de um de nossos entrevistados:

Eles não podiam imaginar o engajamento e o interesse tão grande dos consumidores nessas reuniões. Porque são reuniões mensais, tem eventualmente reuniões que são duas vezes por mês, reuniões um turno todo assim, às vezes com algumas tarefas que a gente tem que levar para a casa e eles ficaram muito surpresos e contentes, a própria SMIC, o Ministério da Agricultura, os próprios agricultores desse interesse e engajamento dos consumidores. Isso foi uma coisa nova que antes nunca havia realmente.

O protagonismo dos consumidores no Conselho de Feiras acompanha o crescimento geral no número de pessoas que semanalmente frequentam esse sistema de abastecimento alimentar de Porto Alegre. Observaçóes colhidas a campo indicam que esse cenário é resultado de um feixe de causas bastante amplo, que, em boa medida, convergem para as ponderaçóes de Barbosa (2009) acerca das transformaçôes do mundo da alimentação na

10 A Emater-Ascar é a agência do estado responsável pela assistência técnica prestada aos produtores, bem como pela execução da política de extensão rural no Rio Grande do Sul. Criada há 60 anos, é uma empresa de economia mista e sem fins lucrativos. 
sociedade contemporânea. Para essa autora, o ato de comer converteu-se simultaneamente num ato político e ideológico singular e numa experiência multissensorial e de lazer.

Comprar na feira significa, entre outros aspectos, abrir mão das comodidades obsequiadas pelos hipermercados (fácil acesso, possibilidade de compras a prazo, segurança, facilidade de estacionamento etc.) em nome de um sistema regido por uma outra lógica (compras à vista) através de um contato direto com o próprio produtor e mediado por uma intensa troca de informaçóes. Para boa parte dos seus frequentadores, percorrer o espaço da feira significa, também, uma atividade de entretenimento marcada pelo intenso diálogo entre produtores e consumidores, situação esta que é diametralmente oposta ao que se verifica no interior dos supermercados, onde a interação eventual com o funcionário de turno se resume à pesagem de produtos apanhados na gôndola, cuja origem e condiçôes de produção são normalmente desconhecidas.

Barbosa (2009) menciona a existência de algumas tendências da alimentação contemporânea, quais sejam, a cientificação, saudabilidade, valorização de origem e gastronomização. A cientificação decorre do impacto da ciência na sociedade contemporânea, influenciando a tomada de decisão das pessoas sobre o que é mais seguro consumir. No âmbito da cientificação, Barbosa (2009) refere o domínio da 'medicalização', envolvendo a "predominância de um discurso nutricional e médico acerca da alimentação que enfatiza o alimento em detrimento da comida" (BARBOSA, 2009, p. 23). Nesse contexto, os alimentos são percebidos como instrumentos de promoção da saúde ou da doença, sendo "hierarquizados em uma escala de saudáveis e não saudáveis que oscila permanentemente na razão direta das novas pesquisas científicas" (BARBOSA, 2009, p. 24).

A saudabilidade está diretamente relacionada com a medicalização. Todavia, vai mais além ao preconizar outros aspectos que contemplam, por exemplo, as condiçóes técnicas de produçáo, incluindo o respeito aos imperativos da sustentabilidade do ponto de vista ambiental e social, bem como o sabor natural dos alimentos em detrimento do uso de aditivos, colorantes, estabilizantes e conservantes usados nos produtos industrializados. 
O depoimento a seguir traduz esse movimento em direção a uma concepção de qualidade que extrapola os cânones formais do ato alimentar. Nosso entrevistado, assíduo consumidor das feiras da capital gaúcha, começa sua fala descrevendo as armadilhas que se ocultam por detrás da ideia de buscar o preço mais baixo, assim como o mito de que o produto orgânico é sempre mais caro. Por fim, menciona outros aspectos que estão implicados no sistema de preferências em torno ao artigo adquirido nas feiras orgânicas de Porto Alegre, os quais se conectam com as tendências aqui elencadas:

O preço pode até não caber no bolso de todo mundo, mas no momento que tu consomes de um produtor, muitas vezes de um assentado, o que tu estás fazendo? Além do cuidado umbilical da tua saúde, tu está também fazendo uma coisa social, tu estás cuidando do meio ambiente, tu estás viabilizando a permanência de um agricultor na terra. Muitos feirantes de feiras orgânicas só se viabilizam porque eles vêm, pegam a sua caminhonetezinha e trazem pra Porto Alegre.

A questão da origem passa a ser valorizada como atributo atinente aos produtos frescos (in natura), mas também àqueles oriundos de processos de transformação, como no caso de indicaçóes geográficas (denominações de origem e indicaçóes de procedência) de vinhos, queijos e uma plêiade de alimentos portadores do que se convencionou chamar "signos distintivos de qualidade".

Já a gastronomização supõe a conversão do 'ato alimentar', de uma condição banal e rotineira, para uma experiência ligada à fruição, à valorização das tradiçóes culinárias, de saberes e dos sabores associados à comida. Essa tendência foi referendada na fala da maioria de nossos entrevistados, especialmente quando aludem ao gosto diferencial dos produtos adquiridos nas feiras orgânicas em questão. A satisfaçáo produzida serve, inclusive, para justificar eventuais diferenças de preço frente ao produto convencional (não orgânico) comercializado em outros locais da capital gaúcha:

No geral eu não acho que seja caro. Eu pago tudo! Tipo assim, tu vês na rua, na época do morango, os caras vendendo aquelas caixinhas de morango por nada, tipo 4 a 5 pilas [reais]. E aqui [nas feiras orgânicas] 5 a 6 reais [...]. Eu prefiro comprar o morango deles mais caro. Porque eu sinto a diferença no gosto, em quase tudo. Se eu compro um tomate que não é da feira, eu sinto, se eu compro uma verdura que não é da feira, eu sinto. 
A grandes traços desenhado, esse é o contexto em que se inserem as feiras orgânicas de Porto Alegre, assim como a dinâmica geral que rege atualmente o seu funcionamento. A tarefa que se nos impóe agora é desvelar os elementos que, na nossa acepçáo, aproximam a realidade dessas feiras a um movimento mais amplo que exalta a dimensão crítica e política do consumo agroalimentar.

\section{Práticas de consumo crítico e construção da qualidade}

$\mathrm{O}$ perfil dos consumidores e frequentadores das feiras apresenta variações do ponto de vista da idade, gênero, situação social etc. Estudos realizados no Brasil (PEREIRA et al., 2015; OLIVEIRA; SILVA; FOSCACHES, 2012) e em outros países (BRUNORI; ROSSI; GUIDI, 2012) indicam que o grau de escolaridade e o nível de renda dos consumidores de produtos orgânicos tendem a superar os de consumidores de produtos convencionais. A aproximação realizada junto às feiras orgânicas de Porto Alegre mostrou que a percepção da realidade e o comportamento de seus frequentadores vão além da realização de uma simples operação de compra e venda de produtos de primeira necessidade e de alto valor agregado. Não raras vezes, a avaliação desse fenômeno conduz para uma explicação simplista de que esse tipo de mercado de proximidade é o resultado da ansiedade de uma elite consumidora no afá de preservar a própria saúde. $\mathrm{O}$ depoimento de um de nossos entrevistados situa a questão nos seguintes termos:

É uma outra forma de ver o mundo, de começar a ver as coisas diferentes. De criar uma outra mentalidade, uma outra consideração. Que não parte só da consciência do alimento. Não parte só da coisa de conscientizar, não é só a coisa da saúde. Eu adoro esta coisa da alimentação, da saúde, mas não é só isso. É que envolve outras coisas, uma outra forma de pensar o mundo. Outra coisa que eu acho legal é a coisa da simplicidade. As pessoas são mais simples na feira. Então eu acho uma coisa boa.

A hipótese central de que partimos ao realizar esta pesquisa reside no entendimento de que a adoção de práticas alimentares e de hábitos sustentáveis de consumo ultrapassa o âmbito hedonista da mera satisfação pessoal. Estudos como os de Sassatelli (2004) recalcam sobre a importância da transição rumo a uma outra visão de mundo e a um novo estilo de vida. 
Para os efeitos que persegue este artigo, vale indagar: como se apresentam as práticas de consumo crítico e de construção social da qualidade no contexto das feiras orgânicas de Porto Alegre?

A compreensão da realidade varia consideravelmente entre os consumidores, indo desde posiçóes que exaltam os atributos tangíveis dos produtos adquiridos nessas feiras, até os que remetem às formas de agricultura que lhes correspondem. A fala de um de nossos entrevistados (consumidor) é bastante ilustrativa na medida em que mostra o grau de entrelaçamento dos eixos da transição operada simultaneamente na mente de produtores e de consumidores:

Da mesma forma que nós, consumidores, fomos aprendendo, na época, quando começamos esse processo, fomos considerados pessoas bicho-grilo, pessoas anormais - imagina - pessoas querendo voltar ao passado, a mesma pressão eles receberam, não sei se num nivel mais profundo [...]. E eles sofreram muito com isso. Eles sofreram muito quando juntou o estereótipo Jeca Tatu, de ignorante, de burro, de trouxa, de ingênuo. E essa imagem ainda existe muito no interior. Então o agricultor evoluido é o do agronegócio, tem que ter grande extensão de terra, tem que plantar só uma coisa [...]. Eles tinham vergonha de dizer que era uma produção orgânica. Hoje eles têm orgulho. E os outros que tinham orgulho de dizer que botavam veneno e usavam tecnologia, hoje eles têm vergonha.

Os dados mais recentes mostram um vertiginoso incremento no consumo de orgânicos pelas razóes anteriormente expostas. Todavia, diversos são os estudos que denunciam os riscos do processo de "convencionalização" (GUTHMAN, 2003; FONTE, 2008), em que esse tipo de produção tende a assumir as mesmas características sociais, técnicas e econômicas da produção convencional. O orgânico nada mais seria do que um 'nicho de mercado' explorado pelas grandes cadeias de distribuição para atender a um consumidor mais exigente e preocupado com a própria saúde. Essa faceta da discussão é bastante relevante e surgiu nas entrevistas, no paralelo que os consumidores das feiras fazem com o produto orgânico adquirido dentro dos hipermercados e/ou em outros âmbitos de comercialização:

Isso é importante! [...]. Eu não compro no supermercado. Mas é engraçado, mesmo se eu vejo orgânico no supermercado não parece a mesma coisa pra mim! Porque ali tá embalado, tá embalado no plástico, ai tem a bandejinha de isopor, já tá ali há uns três ou quatro dias, sei lá... Então, claro, não é a mesma coisa. Na feira o alimento está fresco! 
A maioria de nossos entrevistados tem plena convicção da lógica que impera dentro das grandes superfícies de varejo, estabelecendo-se aí uma relação de exploração que se impóe sobre os pequenos produtores. Nesse sentido, comprar na feira orgânica implica a possibilidade de enfrentar essa dinâmica espúria e de, simultaneamente, valorizar o papel social do agricultor orgânico:

Então, tem que ser assim, ser consciente! Talvez em muitas coisas eu não sou consciente. Mas se eu posso ser justa no sentido de dar a remuneração para a pessoa que está lá trabalhando de sol a sol, se eu posso fazer isso, eu vou fazer isso. Diferente de pessoas que têm uma grande rede de supermercados, têm um capital envolvendo, eles fazem pressão, muitas vezes, pela força da compra deles. Então eles tão pressionando a pessoa que está lá a ganhar menos. Então, se eu posso fazer diferente, eu vou fazer diferente.

Em Porto Alegre, a rede de hipermercados Zaffari"', não obstante o conceito construído nas quatro últimas décadas de qualidade dos produtos comercializados em suas lojas, é refém de um esquema de distribuição marcado pelo desperdício de energia que vai do uso estendido de embalagens plásticas à importação de produtos de regiôes distantes, típico de cadeias longas de suprimento. Nesse caso, comprar direto do produtor é um ato que produz significado e faz toda a diferença:

Na verdade, assim, tem uma questão de Porto Alegre que é um problema. Porque não tem competição, é uma marca só de supermercado. Só vai no Zaffari. E o que eu acho de supermercado é que na feira tu compra direto do produtor. Quanto menos atravessador, eu acho que é mais. Isto é uma outra coisa que faz diferença. Eu morei um tempo na Inglaterra, e eu conheci um casal que fazia muito isso que é o Fair trade. Você sempre tentar comprar do produtor local, que tem menos impacto. Então o que eu puder fazer nesse sentido eu faço.

$\mathrm{Na}$ mesma linha de raciocínio, outro de nossos entrevistados descreve, com bastante propriedade, como operam os mecanismos que regem o funcionamento dos impérios agroalimentares no que tange às relaçóes estabelecidas com os pequenos produtores:

II O Grupo Zaffari controla um total de 30 hipermercados, que incluem as redes Zaffari e Bourbon de hipermercados e que se concentram na região metropolitana de Porto Alegre e metade norte do Rio Grande do Sul. 
O Walmart, o Nacional'2, que tem o Walmart por trás, tem essa política, então é o seguinte, ah, o cara compra hoje I mil pés de brócolis, nós negociamos o preço. Ai, daqui a pouco, o cara diz: bah, que brócolis bom, precisamos de 2 mil, tu tens? Tenho... Bah, abri uma loja nova, assim e assado, em tal lugar, que é garantido que vai vender, tu podes produzir 10 mil? E o cara tem que investir não sei o quê, e leva um tempo, e ai ele investe pra produzir 10 mil e [aí] ele deixa o cara na mão. Agora nós vamos te pagar 30\% a menos, e o cara é trabalha dez vezes mais para produzir 10 mil e ganha a mesma coisa! Quem é que ganha?

Entrementes, a feira representa uma oportunidade de reconexão com os ritmos da natureza, a qual se expressa, entre outros elementos, no privilégio concedido aos produtos de estaçáo, em detrimento dos artigos exóticos e/ou oriundos de regiôes distantes, cujas condiçóes de produção são absolutamente desconhecidas. O depoimento de uma entrevistada ilustra bem essa questáo:

Ah, o que tem, o que é do momento, porque é tão bacana essa história de vivenciar a safra dos produtos, né? Porque a gente se esbalda bastante daquela fruta, naquele momento, depois tem uma profunda saudade daquela fruta e ela aparece de novo depois e, quando aparece, é uma alegria tão maravilhosa. Essa semana chegou maçã, quer dizer, acho que uns seis meses que não comia maçã, então chegou pra gente... Ai! Que saudade da maçã, peguei uma sacola, bem uns três quilos de maçã, então a gente vivencia disso, agora daqui um pouco vai chegar a melancia, a uva, frutas de verão. Há pouco, umas duas, três semanas chegou o pêssego, que é outra fruta que a gente adora, as crianças gostam.

Vivenciar o calendário das frutas, legumes e verduras e a dinâmica subjacente à operação das feiras é também uma experiência cognitiva, de "lidar" com os desafios de alimentar-se segundo os rumos de uma atividade - a agricultura - que é tributária do clima e sempre sujeita às incertezas. Nos dois depoimentos, a continuação dessa faceta do mundo das feiras é descrita nos seguintes termos:

Sempre tem cítricos e banana, então isso, por exemplo, agora tá na época do abacaxi, vai ter mais um pouco, dai vai acabar o abacaxi de novo, dai vai começar a uva que eles adoram, vai começar a melancia, o morango agora em função das estufas eles tão conseguindo ter quase que o ano todo, então a gente já lida bem com isso assim. As crianças às vezes perguntam: Mãe, tô com saudade de comer pêssego, quando vai ter pêssego ou

12 A Wallmart é uma multinacional norte-americana que controla três grandes redes (Nacional, Maxxi e Big), perfazendo 87 hipermercados existentes no Rio Grande do Sul, sendo que 17 deles estão situados em Porto Alegre, 23 na região metropolitana e 47 no interior do estado. 
quando vai ter caqui? Porque eles já sabem que tem um tempo que tem que esperar, a natureza não dá sempre. (grifo nosso).

Como eu vou ali na feirinha, muita coisa eu me informo ali mesmo. É ali, muitas coisas eu fico conhecendo ali. Enfim, mas até não daquelas de ficar se preocupando 'o que é bom para o estômago, o que é bom para o cabelo'. Porque eu acho que as coisas um dia é bom, outro dia já não é bom. Então eu nem ouço estas coisas. Então eu me informo assim pela midia normal e muito assim, pela feira, que eu observo, assim. [...]. Então como eu fui acompanhando assim a evolução? Tu acabas te afeiçoando ali, com o pessoal. E cada vez tu valorizas mais aquele produto. Acho que foi assim.

Ao analisar a experiência dos Grupos de Compras Solidárias no Mezzogiorno italiano, Sivini (2013, p. 51) argumenta que a lógica que orienta o consumidor crítico que participa desse tipo de iniciativa expressa o esforço no sentido de superar os limites impostos pela individualizaçáo do ato de consumo de alimentos que marca a sociedade contemporânea. Todos os nossos entrevistados assinalaram a importância do compartilhamento de informaçóes, bem como de um compromisso tácito de valorizar o trabalho dos produtores orgânicos e de mostrar que não estão sozinhos nessa empreitada. Essa comunidade de interesses se estrutura em torno de valores fundamentais, sobretudo na confiança cultivada entre produtores e consumidores:

[...] já fui na casa dos produtores, tenho crédito, esqueço de pegar dinheiro eu vou lá e tenho crédito, esqueço a sacola e eles me dão uma caixa, a relação lá não é umbilical, é visceral! Então eu defendo aqueles caras com unhas e dentes, e a gente que é consumidor, por exemplo, que é contra assentados, essa coisa de movimento, né, MST, esses caras estão fazendo o trabalho deles direitinho, são os caras que estão aqui e tão produzindo, esses feirantes não são atravessadores, ou seja, uma das regras da feira é vender a própria produção.

Há, destarte, um aspecto pouco analisado nos estudos sobre a dinâmica das redes agroalimentares alternativas e, mais precisamente, sobre aquelas redes voltadas à produçáo e comercialização de produtos orgânicos. Referimo-nos ao fato de que ao agricultor é dada a possibilidade de romper com a dualidade perversa entre o 'produzir para vender' e o 'produzir para comer'. Em outras palavras, podemos afirmar que os produtores orgânicos das feiras de Porto Alegre não vivem esse dilema, ou mesmo esse complexo de culpa que marca a agricultura convencional, em que a lógica do lucro se 
impóe em detrimento do esforço de reduzir ou mesmo eliminar o uso de agrotóxicos. O depoimento de um de nossos entrevistados, que participa ativamente das feiras do bairro Bonfim, é bastante enfático ao narrar um fato que ilustra com propriedade essa questão:

O repórter foi entrevistar um dos guris, o Elemar, que era feirante. O Schmitz tinha dois filhos, o Jeferson e o outro não me lembro o nome, um dos dois foi entrevistado pelo repórter, 'bah, não sei o quê, os moranguinhos gostosos', aquela coisa de falar com criança, $e$ não sei como, veio uma resposta que era assim 'os vizinhos também plantam morangos, mas quando eles querem comer eles vêm pegar da gente', isso deu um problema que quase desestruturou o cara, porque criança não mente, foram boicotes na escola, trotes na escola, foi um troço assim que viver na comunidade foi complicado! Uma coisa de contaminação, uma coisa de falta de ética, eu acho que vem do ser humano e ai tu pega as pessoas produzindo, botando veneno e vendem porque é para os outros, é uma falta de ética!

A sinceridade do menino mostra que sua família atua dentro de um contexto em que produzir morangos sem usar veneno é quase uma quimera nas atuais circunstâncias. Por outra parte, as pessoas que frequentam as feiras estão conscientes, em maior ou menor medida, do que isso significa. A confiança nos produtores é a base de uma relação construída ao longo do tempo, mas há outro ângulo através do qual é possível aquilatar a singularidade das feiras orgânicas de Porto Alegre.

Com efeito, nas manhãs frias de inverno, aos frequentadores das feiras é dada a possibilidade de provar um 'sopão' elaborado pelos próprios feirantes do bairro Menino Deus, mais uma evidência de que vem sendo construída uma comunidade de interesses pautada em valores que destoam frontalmente da competição e do individualismo que marcam a sociedade atual.

Mas de pouco tempo pra cá, que eu vi que eles fazem uma sopa pra todo mundo. Todo mundo vai ali e come. Não é só para os feirantes. Eu tô a fim, eu vou ali, me sirvo e como. Um dia frio eles fizeram um sopão. Eu achei o máximo isso! Então, assim tem aquela coisa agregadora, aquela, uma outra mentalidade. A mentalidade da confiança, tanto que o feirante deixou eu ficar devendo feijão que custava doze reais o quilo e ele mesmo falou pra mim: 'aqui a mentalidade é outra. Imagina se eu não puder confiar em ti!' Então eu achei o máximo isso!

Há, não obstante, diversos desafios a serem enfrentados. Administrar as feiras pressupóe um esforço contínuo de produtores, consumidores, 
técnicos da extensão rural e do poder público municipal em aperfeiçoar mecanismos de controle e gestáo. Isso exige tempo e dedicaçáo por parte dos implicados, com o fito de contemporizar eventuais conflitos que vão desde o controle no uso do espaço público, ao estrito cumprimento das normas que regem o sistema brasileiro de avaliação da conformidade orgânica.

No caso dos produtores que decidirem aderir a essa forma de produzir, é requerido um processo de conversão ${ }^{13}$ que pode se estender por, no mínimo, dois anos, período considerado longo por aqueles que têm na agricultura sua fonte exclusiva de sobrevivência e/ou que anseiam o lucro rápido. $\mathrm{O}$ mesmo pode ser dito em relação àqueles cuja racionalidade produtiva foi forjada na visão preconizada pelas tecnologias produtivistas. Também é certo considerar que existe uma pressão constante por melhorias na condução das feiras, tratando-se de processo permanente e dinâmico de aperfeiçoamento em nome dos ideais da sustentabilidade, os quais se expressam em aspectos aparentemente banais, como a eliminação do uso de sacolas plásticas:

Então na feira eu não vejo lado negativo, são coisas assim feitas, coisas a serem aprimoradas, inclusive uma coisa que eu sempre bato na tecla que eu acho que falta coragem dos feirantes é abolir a sacola plástica. [...] 'ah, as pessoas vão usar a sacola plástica depois para o seu lixo orgânico em casa'. Mas é uma sacola a menos!

$\mathrm{Na}$ aproximação realizada nesta pesquisa, constatamos que as feiras orgânicas de Porto Alegre estão sujeitas a dois grandes feixes de pressóes, um de ordem externa, outro de ordem interna. No primeiro caso, o incremento verificado no consumo de orgânicos não pode prescindir de uma ampliação na produção e oferta de orgânicos no médio e longo prazo, situaçáo que exige a inclusáo de novos produtores, o que decididamente não é uma tarefa fácil. Há sempre o risco de incluir agricultores que estão apenas interessados no valor agregado do produto e que podem náo comungar

13 O processo de conversão não se resume a uma questão estritamente técnica no sentido de abolir o uso de produtos de síntese (adubos inorgânicos e agrotóxicos) e sementes geneticamente modificadas e de eliminar a possibilidade de contaminação residual nos alimentos a serem produzidos doravante na propriedade. É também uma ação de natureza econômica, política e social, sendo que um dos grandes objetivos é alcançar a certificação da própria produção e agregar valor ao produto. O Decreto $n^{\circ} 6.323$, de 27 de dezembro de 2007, estabelece que o período de conversão variará de acordo com o tipo de exploração e a utilização anterior da unidade de produção, considerada a situação socioambiental em que se encontra. 
dos valores éticos que nortearam a criação das feiras e a concertação que foi sendo tecida entre os entes envolvidos ao longo de, pelo menos, duas décadas. Vale frisar que o processo de conversão da agricultura convencional à produçáo orgânica requer apoio técnico, investimento e orientaçóes que são cruciais num contexto em que há limites de atuação dos entes públicos diante da escassez de recursos materiais e humanos.

Ainda no plano externo, não podemos minimizar a tendência de 'convencionalização' a que aludimos anteriormente, por intermédio da qual a produção orgânica tornar-se-ia algo banal, traduzida numa simples etiqueta de certificação aderida a um produto comercializado pelas grandes superfícies de varejo para atender às necessidades de consumidores mais exigentes. No plano interno, manter esse sistema de controle e acompanhamento, como no caso das visitas realizadas junto às propriedades rurais, demanda uma boa dose de comprometimento e o ingresso de novos consumidores identificados com uma visão construída ao longo de um intenso processo de aprendizagem e de compartilhamento de informaçóes.

\section{Considerações finais}

Os intelectuais ligados à Escola de Frankfurt manifestavam seu desencanto em relação ao marxismo e à própria razão iluminista, denunciando o modo pelo qual a sociedade ocidental havia destruído os ideais de emancipação social. Destarte, denunciaram também a manipulação da consciência das massas, em meio à edificação de uma indústria cultural que, em grande medida, obstaculiza toda e qualquer forma de pensamento crítico sobre a realidade em que estamos inseridos.

No presente estudo, colocamos especial atenção às transformações profundas que incidem sobre o mundo da alimentação em geral. Tais mudanças podem ser traduzidas na transição semântica operada entre a ideia de alimento e o conceito de produto alimentício. O primeiro termo compreende aquilo que consumimos na forma em que encontramos na natureza, sem aditivos, conservantes ou elementos que alterem sua validade, enquanto o segundo remete a artigos que passaram por algum tipo de interferência ou processamento agroindustrial, alterando a sua forma original. 
O padrão agroalimentar que se impôs desde o final da Segunda Guerra Mundial não poderia ter sido construído sem o advento de uma indústria cultural poderosa e de fortes incentivos governamentais traduzidos na conhecida política do 'cheap food policy', levada a cabo pelos países do capitalismo central e periférico. Esse processo guarda estreitos vínculos com a banalização do ato alimentar e com os grandes escândalos a que fizemos menção na parte inicial deste artigo, os quais conformam uma das facetas que integram a sociedade de risco descrita por Beck e por outros autores.

A emergência de novas formas de solidariedade é vista como desdobramento da necessidade de um agir individual e coletivo diante da magnitude dos problemas que cercam o mundo da comida e da agricultura em geral. Entre essas formas de atuação, consta a criação do que uma ingente literatura internacional denomina 'redes agroalimentares alternativas'. Outra das vertentes por onde transita o debate acadêmico é a perspectiva do consumo crítico, âmbito da reflexão sociológica cuja importância é crescente nas três últimas décadas, sobretudo quando se amplia a convicção do valor cognitivo do ato de alimentar-se e do consumo consciente e responsável.

A ênfase da pesquisa que originou este artigo foi levantar e analisar as práticas de consumo crítico e os processos de construção social da qualidade no contexto das feiras orgânicas de Porto Alegre. Trouxemos à luz as razóes e circunstâncias que motivaram sua aparição, mas também algumas das mutaçóes que elas experimentam ao longo do tempo. Para muitos autores, as feiras em geral, incluindo as orgânicas, nada mais seriam do que um equipamento público de aprovisionamento de comida.

Entretanto, a pesquisa desenvolvida mostrou que se trata de um espaço social singular onde operam muito mais do que simples operaçóes de compra e venda de frutas, legumes e derivados de origem vegetal e animal. Os graus de implicação e compromisso dos consumidores, produtores e poder público é variável. Há desde pessoas que frequentam o espaço em busca de produtos de qualidade, adquirindo-os diretamente de quem os produziu/elaborou, até aqueles que estâo diretamente envolvidos em sua operacionalizaçáo, como as pessoas que integram o Comitê de Feiras, que frequentam as propriedades ou mesmo as comissóes que avaliam o 
cumprimento das normas de avaliação da conformidade da produção orgânica previstas na legislação brasileira.

Não obstante, há um sentido comum e recorrente no que admitimos como o exercício de práticas de consumo crítico, assim como nas relaçóes construídas entre os entes implicados, baseadas fortemente em valores éticos, na confiança e na reciprocidade. Por parte dos consumidores, vimos que a plenitude dos depoimentos acentua a necessidade de valorização do trabalho que os produtores desenvolvem, não somente em gerar artigos de qualidade, mas também em construir um novo pacto social centrado na preservação da natureza para as atuais e para as futuras geraçóes.

Todavia, constatamos também alguns desafios em relação ao presente e ao futuro da experiência em questáo. O crescimento verificado no consumo de orgânicos e o incremento na produção comercializada podem levar ao risco de convencionalizaçáo. Por outra parte, tal expansáo pode induzir a que as feiras sejam vítimas do próprio êxito, sobretudo quando o ritmo desse processo de crescimento impacta sobre um sistema de controle que vem sendo construído de forma participativa, por todos os entes envolvidos.

A crítica ao sistema dominante transparece nas entrevistas de forma clara, náo apenas nos depoimentos que denunciam a incerteza sobre a qualidade e sanidade dos produtos vendidos nos grandes supermercados, mas também na construção de um imaginário acerca de um regime que oprime os produtores rurais por conta das regras de mercado e do ambiente concorrencial de cadeias longas de suprimento.

A importância de apoiar e valorizar o trabalho diferenciado realizado pelos produtores e, especialmente, pelos assentados da reforma agrária emergiu como um traço recorrente nos depoimentos de nossos entrevistados. A realização desta pesquisa colocou-nos diante de inúmeros campos de observaçáo da realidade, como a análise do papel das feiras orgânicas como eixo de fortalecimento de duas bandeiras históricas do movimento ambientalista. A primeira delas compreende os esforços envidados na construção social da agroecologia; já a segunda bandeira está diretamente relacionada com a primeira, envolvendo a tarefa de fortalecer a agricultura familiar e de viabilizar os assentamentos da reforma agrária, sobretudo 
os que se situam na região metropolitana de Porto Alegre. Se a reflexão aqui desenvolvida contribuiu para fomentar o debate sobre essas e outras questóes, damos por assentadas as premissas que marcaram a realização da pesquisa e a elaboração do presente trabalho.

\section{Referências}

ADORNO, T. W.; HORKHEIMER, M. A dialética do esclarecimento. Rio de Janeiro: J. Zahar Editor, 1995 .

ALLEN, P. et al. Shifting places in the agrifood landscape: the tectonics of alternative agrifood initiatives in California. Journal of Rural Studies, v. 19, p. 61-75, 2003.

ALMEIDA, J. A construçáo social de uma nova agricultura: tecnologia agrícola e movimentos sociais no sul do Brasil. Porto Alegre: Ed. Universidade/UFRGS, 1999.

ANJOS, F. S.; CALDAS, N. V.; POLLNOW, G. Vinho, território e desenvolvimento: o caso da indicação de procedência dos vinhos de Pinto Bandeira. In: ANJOS, F. S.; CALDAS, N. V. (org.). Construçáo social da qualidade na produçáo agroalimentar. São Paulo: LiberArs, 2014. v. 1, p. $19-43$.

BARBOSA, L. Tendências da alimentação contemporânea. In: PINTO, M.; PACHECO, J. K. (org.). Juventude, consumo e educaçáo. Porto Alegre: ESPM, 2009. p. 15-64.

BAUMANN, Z. Vida de consumo: a transformação das pessoas em mercadoria. Rio de Janeiro: J. Zahar, 2007.

BECK, U. Risk society. Towards a new modernity. Londres: Sage Publications, 1992.

BECK, U.; GIDDENS, A.; LASH, S. Modernizaçáo reflexiva: política, tradição e estética na ordem social moderna. São Paulo: Editora da Universidade Estadual Paulista, 1997.

BIANCHI, A. M.; MURAMATSU, R. A volta de Ulisses: anotaçóes sobre a lógica de planos e compromissos. Revista de Economia Política, v. 25, n. 2, p. 23-44, 2005.

BOURDIEU, P. A distinção: crítica social do julgamento. São Paulo: Edusp, 2007.

BRUM, A. O desenvolvimento econômico brasileiro. Rio de Janeiro: Vozes, 1987.

BRUNORI, G.; ROSSI, A.; GUIDI, F. On the new social relations around and beyond food. Analyzing consumer's role and action in Gruppi di Acquisto Solidale (Solidary Purchasing Groups). Sociologia Ruralis, v. 52, n. 1, p. 1-30, 2012.

CAILLÉ, A. O princípio de razão, o utilitarismo e o antiutilitarismo. Sociedade e Estado, Brasília, v. 16, n. 1-2, p. 26-56, 2001.

CANCLINI, N. G. Consumidores e cidadáos: conflitos multiculturais da globalizaçáo. Rio de Janeiro: Editora UFRJ, 2010. 
Redes agroalimentares alternativas e consumo crítico: o caso das feiras orgânicas de Porto Alegre | Graciela Cristina Dillemburg Martil, Flávio Sacco dos Anjos

CARSON, R. Silent spring. Boston: Houghton Mifflin, 1962.

CONSTANCE, D. H.; CHOI, J. Y.; LYKE-HO-GLAND, H. Conventionalization, Bifurcation, and Quality of Life: A Look at Certified and Non-Certified Organic Farmers in Texas. Southern Rural Sociology, v. 23, n. 1, p. 208-234, 2008.

DOUGLAS, M.; ISHERWOOD, B. O mundo dos bens: para uma antropologia do consumo. Rio de Janeiro: UFRJ, 2013.

FONTE, M. Knowledge food and place: a way of producing, a way of knowing. Sociologia Ruralis, v. 48, n. 3, p. 200-222, 2008.

FONTE, M. Food relocalisation and knowledge: dynamics for sustainability in rural areas. In: FONTE, M.; PAPADOPOULOS, A. G. (org.). Naming food after places: food relocalisation and knowledge dynamics in rural development. Farnham: Ashgate, p. 1-35, 2010.

FORNO, F. Consumatori in 'movimento': il consumo critico come forma di partecipazione politica. In: GASP: Gruppi di acquisto solidale e partecipativo. Milano: Punto Rosso, 2009.

GARCIA, M. C. Experiências brasileiras com sementes crioulas: relato de uma viagem (bio) diversa. 2004. Disponível em:

http://www.midiaindependente.org. Acesso em: 24 maio 2015.

GIDDENS, A.; LASCH, S.; BECK, U. Modernização reflexiva: política, tradição e estética na ordem social moderna. Sáo Paulo: Unesp, 2012. p. 89-166.

GOLDBERGER, J. Conventionalization, civic engagement, and the sustainability of organic agriculture. Journal of Rural Studies, v. 27, p. 288-296, 2011.

GOODMAN, D. The Quality "Turn” and Alternative Food Practices: Reflections and Agenda. Journal of Rural Studies, v. 19, n. 1, p. 1-7, 2003.

GOODMAN, D.; DUPUIS M. Knowing Food and Growing Food: beyond the productionconsumption debate in the Sociology of Agriculture. Sociologia Ruralis, v. 42, n. 4, p. 5-22, 2002.

GOODMAN, D.; DUPUIS, M.; GOODMAN, M. Alternative food networks. London/New York: Routledge, 2012.

GRAZIANO DA SILVA, J. A modernizaçáo dolorosa: estrutura agrária, fronteira agrícola e trabalhadores rurais no Brasil. Rio de Janeiro: J. Zahar, 1982.

GUIVANT, J. A teoria da sociedade de risco de Ulrich Beck: entre o diagnóstico e a profecia. Estudos Sociedade e Agricultura, v. 16, p. 95-112, 2001.

GUTHMAN, J. The trouble with 'organic lite' in California: a rejoinder to the 'conventionalization' debate. Sociologia Ruralis, v. 44, n. 3, p. 301-316, 2003.

HENDRICKSON, M. K.; HEFFERNAN, W. D. Opening Spaces through Relocalization: Locating Potential Resistance in the Weaknesses of the Global Food System. Sociologia Ruralis, v. 42, n. 4, p. 347-369, 2002. 
HIGGINS, S. S. Fundamentos teóricos do capital social. Chapecó: Argos, 2005.

MARX, K. O capital: crítica da economia política. Sáo Paulo: Nova Cultural, 1985. Livro 1, tomo 2.

MINTZ, S. Comida e Antropologia: uma breve revisão. Revista Brasileira de Ciências Sociais, São Paulo, v. 16, n. 47, p. 31-41, 2001.

MOL, A. P. J.; SPAARGAREN, G. Environment, Modernity and the Risc Society, the Apocalyptic Horizon of Environmental Reform. International Sociology, v. 8, n. 4, p. 431-459, 1993.

O'CONNOR, D. et al. Driving Rural Development: Policy and Practice in Seven EU Countries. Assen: Van Gorcum, 2006.

OLIVEIRA, L. F. D.; SILVA, F. Q.; FOSCACHES, C. A. L. A profile of the Brazilian consumers of organic products. African Journal of Business Management, v. 6, n. 23, p. 6939-6947, 2012.

PEREIRA, M. C. et al. Mudança no perfil sociodemográfico de consumidores de produtos orgânicos. Ciência e Saúde Coletiva, Rio de Janeiro, v. 20, n. 9, p. 2797-2804, 2015.

PLOEG, J. D. V. D. Camponeses e impérios alimentares: lutas por autonomia e sustentabilidade na era da globalização. Porto Alegre: UFRGS Editora, 2008.

PLOEG, J. D. et al. Rural Development: From Practices and Policies Towards Theory. Sociologia Ruralis, v. 40, n. 4, p. 391-408, 2000.

RAWLS, J. Uma teoria da justiça. Tradução de Vamireh Chacon. Brasília: Editora da Universidade de Brasília, 1981.

RENTING, H.; MARSDEN, T.; BANKS, J. Understanding alternative food networks: exploring the role of short supply chains in rural development. Environment and Planning, v. 35, n. 3, p. 393-411, 2003.

RENTING, H.; SCHERMER, M.; ROSSI, A. Building Food Democracy: Exploring Civic Food Networks and Newly Emerging Forms of Food Citizenship. International Journal of Sociology of Agriculture and Food, v. 19, n. 3, p. 289-307, 2012.

RITZER, G. The McDonaldization of society: an investigation into the changing character of contemporary social life. Thousand Oaks, CA: Pine Forge Press, 1996.

RITZER, G.; JURGENSON, N. Production, consumption, presumption: the nature of capitalism in the age of the digital 'prosumer'. Journal of consumer culture, n. 10, p. 13-36, 2010.

ROSIN, C.; CAMPBELL, H. Beyond bifurcation: examining the conventions of organic agriculture in New Zealand. Journal of Rural Studies, v. 25, n. 1, p. 35-47, 2009.

SASSATELLI, R. L'alimentazione: gusti, pratiche e politiche. Rassegna Italiana di Sociologia, v. 45, n.4, p. 475-492, 2004.

SASSATELLI, R. The Political Morality of Food: Discourses, Contestation and Alternative Consumption. In: HARVEY, M.; MCMEECKIN, A.; WARDE, A. (org.). Qualities of Food. Manchester: Manchester University Press, 2009. p. 176-207. 
Redes agroalimentares alternativas e consumo crítico: o caso das feiras orgânicas de Porto Alegre | Graciela Cristina Dillemburg Martil, Flávio Sacco dos Anjos

SEYFANG, G. Ecological citizenship and sustainable consumption: examining local organic food networks. Journal of Rural Studies, v. 22, n. 4, p. 383-395, 2006.

SIVINI, S. Intrecciare reti: agricultori biologici, gruppi di acquisto solidali, turisti responsabili. Catanzaro: Rubbettino, 2008.

SIVINI, S. Pratiche di produzione (alimentare) critica nel Mezzogiorno d'Italia. In: SIVINI, S.; CORRADO, A. (org.). Cibo locale. Percorsi innovativi nelle pratiche di produzione e consumo alimentare. Napoli: Liguori Editore, p.39-59, 2013

WARDE, A. Consumption, food and taste. London: Sage, 1997.

WEBER, M. Ensaios de Sociologia. Rio de Janeiro: LTC Editora, 1982.

VEBLEN, T. A teoria da classe ociosa (um estudo econômico das instituiçóes). São Paulo: Nova Cultural, 1988.

VENTURA, F.; MILONE, P. Innovatività contadina e sviluppo rurale. Milano: Franco Angeli, 2005.

Recebido 12/03/2018

Aprovado 26/08/2019 


\section{Alternative agrifood networks and critical consumption: the case of organic markets in Porto Alegre}

\section{Abstract}

The last four decades coincide with the appearance of what has been called "alternative agri-food networks". Numerous scandals, widespread uncertainty and the search for healthier foods are highlighted in a broader movement called "turn of quality," where the idea of quality goes beyond the product's strict and tangible attributes. The organic fairs of Porto Alegre are part of the transformations that affect the world of food in general. The focus of the study is to elucidate the circumstances that contributed to its emergence, as well as the mutations that this local supply system has experienced since its inception. The research seeks to show that organic fairs consist of a unique social space where they operate much more than food buying and selling operations. Nonetheless, there are challenges in relation to the future, especially the developments arising from the increase in demand and the risk of conventionalization.

Keywords: Short marketing channels. Critical consumption. Free fairs. Organic Agriculture. Agroecology. 